\title{
Perception of Global Issues of Environment and Circular Economy by Generation Z
}

\author{
Iveta Malikova ${ }^{1, *}$ \\ ${ }^{1}$ University of Ss. Cyril and Methodius in Trnava, Faculty of Mass Media Communication, \\ Marketing Communication, , Námestie J. Herdu 2, 91701 Trnava, Slovakia
}

\begin{abstract}
.
Research background: Man has been interfering in the environment with his action since ancient time. At the very begging, these were only small interventions, but with scientific and technical development, the interconnection of national economies and the growth of population and consumptions, these interventions are so significant that there is a risk of depletion of some non-renewable resources and degradation of the natural environment. Experts have agreed that these are problems with a global dimension and they have been pointing out the need to address these issues for decades.

Purpose of the article: The paper is aimed at representatives of the $\mathrm{Z}$ generation in order to show how this generation perceives the current global environmental issues and what is their view on the application of the circular economy in practice.

Methods: Survey analysis.

Findings \& Value added: There are many companies which are aware of the fact and they have started to apply the concept of the circular economy in order to eliminate the negative effects on the environment. This concept consists of using fewer resources in the production of new products through more efficient process and the prevention of waste trough reuse, repair treatment and recycling. All product and material flows will be reintegrated into their cycle after their use, where they will subsequently become resources for the production of the new products and services. Companies that put this concept into practice can gain a competitive advantage in the market by providing consumers with products which are more durable, innovative and mainly environmentally friendly.
\end{abstract}

Keywords: global issues; environment; circular economy; generation $Z$

JEL Classification: $Q 56$

*Corresponding author : iveta.malikova@ucm.sk 


\section{Introduction}

The world around us is constantly changing and transforming. We are increasingly aware of the changes which are happening and which are having an impact on society, economic growth but also on the environment. In recent decades, the development of humanity has undergone a certain transformation, which not only now, but also in the coming years, will continue and affect all generations. What our predecessors could not even imagine years ago is now obvious and makes a part of our everyday life. Indeed, rapid technological development, gradual globalization, access to markets are today considered normal, even desirable. The life of each of us has thus become more demanding, faster, more consuming and stressful. The world development of which undoubtedly we participate, has opened the doors all over the world. Opening of different markets, the above-mentioned globalization and many other factors have an impact on today's behaviour of all of us and on the needs and requirements of our society, which are completely different from the past. "The needs and values of the population, they move in an environment of overproduction (more products are produced than the total social need, companies achieve higher profits) and over-consumption (more products are consumed than is the total social and individual need and purchasing power of the population, there is a higher consumption of non-renewable resources and their waste) ". [1]

These far-reaching changes in society, as well as the changes that have taken place under the influence of the digitized global market, cannot be ignored. Whether we like it or not, these aspects such as generational development, increase of digitalization, globalization and technological advances are transforming the world. Based on these changes and transformations, we have to realize that keeping up with these fundamental changes is the key to succeed.

As we have already mentioned, the changes also affect the country's economic growth. Nowadays, we are truly aware that economic intensification and economic growth are having many negative effects on the environment. Global warming, deteriorating of air quality and insufficient primary resources, make a significant threat to ecosystems and consequently to the future generations. If a company does not cope with this issue, the consequences can be catastrophic very soon. In practice, this means eliminating or significantly reducing interventions that threaten, damage or destroy conditions and life forms, not burden the landscape beyond tolerable levels, use its resources wisely and protect the cultural and natural heritage. If we want this process to be sustainable, it should be long-term targeted, comprehensive and strategic. At the same time, it should affect the conditions and all aspects of our life (cultural, social, economic, environmental and institutional) at all levels (local, regional, global). [3] Taking into account that the national economic growth depends on the environment. Moreover, its protection is a condition for economic and social development and at the same time, part of the sustainable development strategy, which should be a milestone in addressing these impacts of current global financial and social development. A stable economic environment is a condition which leads to the elimination of unemployment and the rational use of all resources and public finances, especially in time of facing an economic crisis while we are struggling to ensure economic growth. Adherence to the principles set out in the strategy of sustainable development and implementation of measures to ensure it, not only solves partial environmental problems for all countries, but also forms a basic prerequisite for further successful progress of both the Slovak and European economies and sustainable growth of living standards. [12,13,14,15] At present, the criteria of environmental quality and real depletion of natural resource reserves have become equal determinants of economic growth and makes part of the green economy. [3] The green economy is an economy that promotes 
human prosperity and social equality while significantly reducing environmental risks and environmental damage. [10] According to UNDESA, a green economy is:

- a tool for achieving sustainable development,

- creating green job opportunities at the same time,

- uses effectively the necessary natural and energy resources,

- when using natural resources, respects their boundaries, ecological limits and restrictions, and protects biodiversity and ecosystems,

- emphasizes on the application of integrated decision-making processes in practice,

- monitors not only the development of GDP, but also other appropriate indicators,

- applies the principles of equality and justice in and between countries and generations,

- contributes to reducing poverty, increasing well-being, improving people's living conditions, ensuring their social protection and access to essential needs,

- internalises negative environmental externalities,

- improves the system of governance and its legislative system,

- is inclusive, democratic, collective, accountable, transparent and stable. [11]

\section{Circular Economy}

Current society, with its high consumption, puts enormous pressure on the entire planet. As a result of the products and services growing demand, the demand for energy and natural resources is also growing. The way how we produce and then consume products is not sustainable anymore. At the same time, this method of consumption contributes greatly to the emerging ecological threats, the accumulation of waste, poor management and intolerable wasting of basic important resources such as water, natural raw materials, or pollution of the nature in general. At the top of that is necessary to realize that the limits of the planet are not unlimited, so we can no longer work with this current way of managing. It follows that we must keep as many resources, materials, products as possible in circulation for as long as possible in order to create the lowest possible pressure on natural, energy and material resources. [7] Equally, we must think of future generations who, like us, will want to satisfy their needs and live in an environment that will not endanger their health or well-being. Many companies are aware of this fact and in an effort to eliminate the negative impacts of their business activities on the environment, they gradually moved to the so-called circular economy, which, unlike the linear economic model, should maintain as long as possible the value of the materials and energy used in the manufacturing of products, minimize waste and use the primary raw material resources. In practice, this means that already during the production, they responsibly approach the selection and use of suitable resources, so that the end result is a product that will be recyclable after consumption and returned to a circulation as a material suitable for the production of a new product. Such a systematic approach minimizes harmfulness of waste at source while maximizing recycling. It defines the circular economy as "a system that allows the added value of products to be maintained for as long as possible while waste is eliminated. At the end of the product life cycle set in this way, the resource (or resources) is preserved within the economy, so the product or component is used multiple times and then forms another value." [5] Due to the fact that the greatest environmental challenges, not only in Slovakia, are increasing the efficiency of resource use through augmenting recycling of waste, which is returned to the production as a secondary material, is indeed necessary to prevent adverse economic, social and environmental developments. Of course, "a balance of economic, social and ecological aspects of the life of a prosperous society that will use its resources sparingly, while sustainability is not just a goal, but an ongoing process in which it is necessary to deal with the most pressing and current issues, " [9] in 
order to improve the quality of the environment, protect human health, rational use of natural resources, minimize waste and promote measures not only at the regional level but also at the international level. Because the circular economy can support the competitiveness and innovation of businesses, it is important that these businesses accept the ongoing changes while adapting to economic conditions. In particular, they need to introduce new methods, tools and techniques, set ambitious targets, emphasize on a sustainable performance, pursue a comprehensive set of economic criteria, pursue strategic innovation, create a dynamic and flexible organizational governance structure and continuously improve key competencies. [2] Those who cannot adapt do not have a chance to succeed in the tough competition in the market. The result is the demise of business entities that can not assimilate with the new conditions. For this reason, each company must set its own success process and be adaptable to the constant changes in the economy. [6]

\section{Results and discussion}

The aim of the survey was to show how the Generation $\mathrm{Z}$ perceives the current global environmental problems and what they think about putting the circular economy in practice. 256 respondents belonging to the Generation $Z$ took part in this online survey.

A Generation Z, (English - Post-Millennials, iGeneration, Plurals), is the generation that follows the Generation Y. According to demographers, these are young people who were born from about the mid-1990s to about 2012. Today the Post-Millennials are the most global and multicultural generation [8]. Technologies have become part of their daily lives since they were born. Because they are constantly online, they know no limits in access to information or in connection with people around the world. Geographical boundaries are no longer an obstacle for them, because almost everything can be found online and the connection to people from all over the world can be done in a few seconds. Globalization also eliminates borders between people of different backgrounds. Representatives of this generation have the freedom to meet different people, try out different interests, join different communities and actually broaden their horizons. Therefore, there is no right or wrong, normal or unusual for them. Their strong point is competition in various areas of their lives, whether at work, school or sports. We can say about the representatives of this generation that they like all changes that life proposes them and they are also very willing to learn new things. Thanks to modern technologies, they gain enough information on any topic, which allows them to expand their knowledge, draw inspiration, which makes them even more creative. Despite how much time this generation spends online, it is the generation that is more interested in the environment than any previous before. This generation is also more ethnically and demographically diverse. Compared to all other generations, they do not deal with racial or sexual differences. The biggest difference of the Generation $\mathrm{Z}$ is the fact that they prefer independence over all, they want to be successful in their own way and do not like to rely on teamwork. This reflects their enormous creativity and especially their struggle for uniqueness, where they try to promote their values and ideas. Resilience of this generation is also reflected in a deep understanding of environmental problems.

The survey shows that the respondents of this survey are interested in different areas. $68 \%$ of the respondents follow information about social events, $38 \%$ are interested in sports (especially men), $27 \%$ in culture, $32 \%$ in the environment, $15 \%$ in information related to the economy and $12 \%$ in politics. $22 \%$ of them indicated another possibility, including information about their hobbies (travel, recipes, lifestyle and inspiration, interesting personalities, etc.). The answers obtained also showed that their quality of life is mainly influenced by economic factors, as was indicated by $87 \%$ of the respondents. Therefore, 
these findings were expected because it is a generation of young people who are beginning to get acquainted with the work environment, looking for opportunities to find a job. It is a generation that is not yet financially secure, but we can say that this generation is able to follow their dream and they are not afraid of challenges. In addition, they want to become independent as soon as possible and if we take into account their interests, such as new technologies, travelling, we can only agree that economic factors are important and affect the quality of their lives. Alike economic factors, social factors are equally important to the respondents of this generation (83\%). This result was expected, because they have used modern technology since early childhood, through which they have been and still are in close contact with its peers and acquaintances, with whom they share various information, express opinions or pieces of advice. For this reason, a social contact has been an important part of their life which forms their personality and helps them to create attitudes to various problems. One of the problems that matters a lot, is the state of the environment, which is not indifferent to the $64 \%$ of the respondents. According to them, these issues need to be addressed properly because they are threats not only for the current population but also for all future generations. Overall, these problems have a strong negative impact on their health, nature itself and obviously on their quality of life. As part of the survey, we also found out which associations these respondents associate with the environment.

The fact that this generation is interested in the environment can also be seen in the scheme of the individual answers, where they are currently associated with the most urging problems within the environmental associations, such as climate change (58\%), natural disasters (43\%), growing landfills (42\%), pandemics affecting the population $(37 \%)$, air pollution from harmful emissions $(38 \%)$, as well as water pollution and depletion of natural resources. The individual findings are shown in Chart 1.

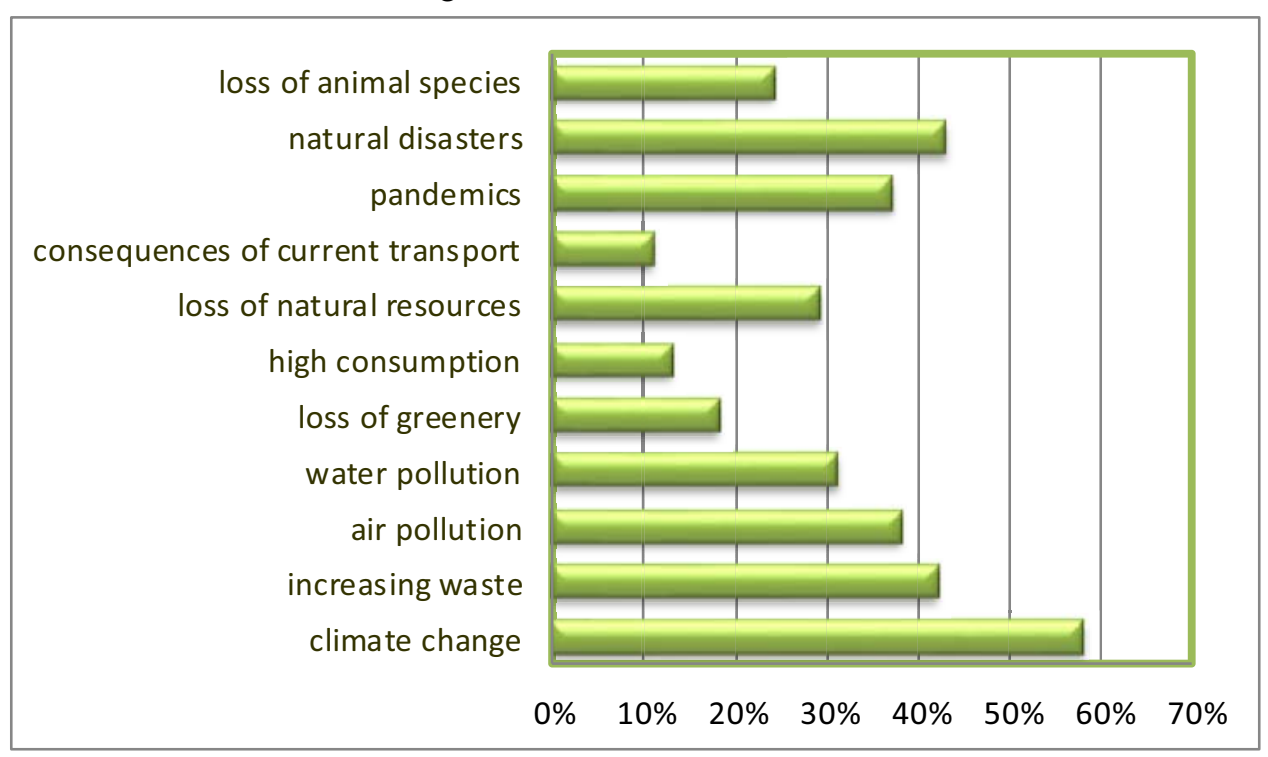

Fig. 1. Associations connected with the environment.

Based on the associations that respondents associate with the environment, our scope was to find out whether these respondents think to know the causes of these individual problems. The $47 \%$ think that they know the causes, they are interested about it and even search for further information. The $45 \%$ partially know the causes, but do not particularly deal with them. The next question was if they knew how to solve these problems. $53 \%$ of the respondents said they knew what we should do to avoid burdening the environment. 
$44 \%$ of the respondents think they have some information, but do not consider it sufficient. At the same time, $82 \%$ of the respondents agreed with the statement, $18 \%$ agreed partially, that the economic growth of the country has an impact on the state of the environment. In connection with this question, we asked the respondents if they agreed with the statement that the economic growth of the country always damages the environment. $19 \%$ of the respondents agreed with this statement, $54 \%$ of the respondents only partially agreed and $27 \%$ do not agree at all. In the survey, we also found out whether the respondents think that the current way of functioning of our national economy is sustainable. On this issue, $67 \%$ of the respondents said that this way of working is certainly not sustainable and that the necessary measures need to be put in place as soon as possible to ensure the national economic growth has minimal impact on the environment. $21 \%$ of the respondents think that this way of functioning of the economy is only to a certain extent sustainable. They also suggested that, in the end, some solutions will be necessary to be adopted, because we need to think about future generations. Otherwise, huge damage to the environment may occur in the near future (loss of natural resources, pollution, air, water, etc.). Due to this fact, many companies have switched to the so-called circular economy, which is based on the fact that the produced products produced do not end up as waste after consumption, but are used for the production of new products. We were interested about what the representatives of the studied generation thinks about it. $63 \%$ of the respondents said that it would help not only the national economy, but also the environment (71\%) and actually reduces the amount of waste produced $(75 \%)$. In this context, more than half of the respondents stated that they had experience with the product thus produced. The last question was focused on environmental protection, especially how the respondents get involved in. The survey shows that, as part of the environmental protection, these respondents were trying to separate waste $(83 \%)$, reduce plastic bags when shopping, as well as all products in plastic packaging (46\%), save energy (31\%), water (34\%), buy ecofriendly products $(29 \%)$, use more environmentally friendly kind of transport (22\%), etc. The individual findings are recorded in Chart 2.

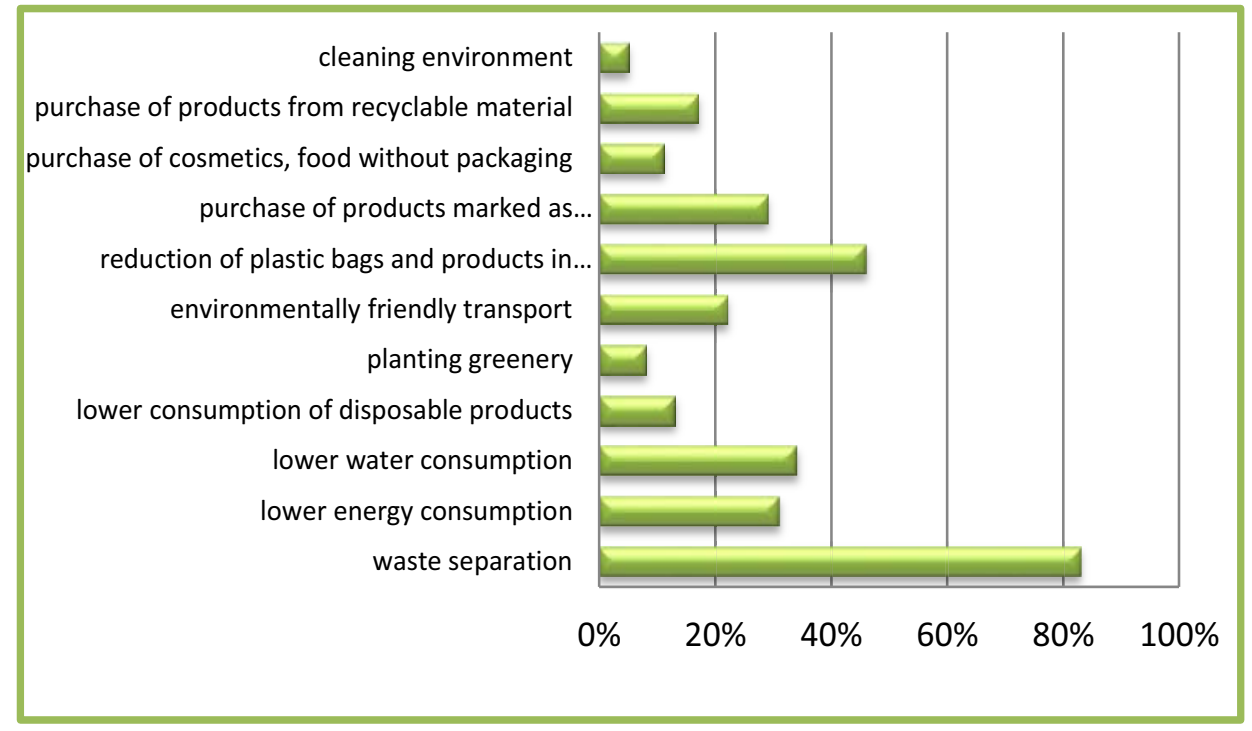

Fig. 2. Commitment at the environemnt protection. 


\section{Conclusion}

Considering that environmental problems affect all of us, we need to pay them special attention, because simply ignoring them can have catastrophic consequences in the future. The aim of this paper was to emphasize the need for the transition to a green economy or a circular economy, which can help reduce the negative environmental impacts of current management and also show how the Generation $\mathrm{Z}$ perceives latest global environmental issues and gives their opinions on applying of the circular economy in practice. Based on the obtained results, we can state that the Generation $\mathrm{Z}$ is a generation of young people who care a lot about living in an environment that does not burden the nature and does not endanger their health and the health of future generations. Actually, it is a generation that is aware of the seriousness of these often discussed problems, is concerned about the national economic growth and environmental protection, and in this context seeks to take appropriate measures such as recycling waste, reducing emissions by giving priority to bicycles and eco-friendly transport. They prefer paper packaging over plastic, try to plant greenery and also eliminate waste and dirt in the nature and living areas, etc. Last but not least, Generation $\mathrm{Z}$ focuses on alternative energy sources, for example, they prioritise electric cars that do not cause harmful air pollution or high fuel emissions. Another significant change is their open-minded view on a vegetarian diet, and consequently many of them try to eliminate meat consumption to a minimum, which also significantly benefits the environment. The elimination of animal products thus forces organizations to produce products that do not have to be tested on animals and are eco-friendly. There are many examples of how Generation $\mathrm{Z}$ is committed to protecting the environment. In conclusion, we can only hope that the representatives of this generation will continue with these activities and thus contribute to the national economic growth in a more environmentally friendly way.

This paper was created within the project VEGA no. 1/0078/18 entitled "Aspects of marketing communication in the management processes of the circular economy."

\section{References}

1. Hes, A., Hesova, I. (2016). Aspects of global communication in post modern society. In : Kliestik, T. (Eds.), Proceedings of 16th International Scientific Conference Globalization and Its Socio-Economic Consequences (636-645). Rajecke Teplice : Conference Proceedings.

2. Jackova, A. (2015). Modern business management and management accounting. In : Kliestik, T. (Eds.), Proceedings of 15th International Scientific Conference Globalization and Its Socio-Economic Consequences (247-253). Rajecke Teplice : Conference Proceedings.

3. Kanianska, R., Jadudova, J., Markova, I. (2020, July 3). Green Economy. Banska Bystrica: Published at the University publishing house of Matej Bel in Banska Bystrica.

4. Circular Economy: A visionary plan? (2020 July 20) Retrieved from: https://www.basf.com/sk/sk/we-create-chemistry/creating-chemistrymagazine/resources-environment-and-climate/circular-economy.html

5. Matova, H., Kaputa, L. (2017). Green preferences of generation y. Proceedings of In : Kliestik, T. (Eds.), Proceedings of 17th International Scientific Conference 
Globalization and Its Socio-Economic Consequences (1510-1517). Rajecke Teplice : Conference Proceedings.

6. Richnak, P. (2015). Globalization and its impact on the present concepts in company management. In : Kliestik, T. (Eds.), Proceedings of 15th International Scientific Conference Globalization and Its Socio-Economic Consequences (608616). Rajecke Teplice : Conference Proceedings.

7. Solymos, L. (2016, August 15). A greed economy is a necessity: We must change the way of our thinking says Sólymos Retrieved from: https://www.topky.sk/c1/100535/1572829/Zelena-ekonomika-je-nutnost--Musimezmenit-sposob-nasho-myslenia--tvrdi-Solymos

8. Sparks \& Honey. (2020, August 18). Generation Z 2025: The final generation. Retrieved from : https://reports.sparksandhoney.com.

9. Salkova, D., Regnerova, M., Hes, A. (2015). Global extent of food waste. In : Kliestik, T. (Eds.), Proceedings of 15th International Scientific Conference Globalization and Its Socio-Economic Consequences (755-763). Rajecke Teplice : Conference Proceedings.

10. UNEP. 2011b. (2020 July 20) Restoring the natural foundation to sustain a Green Economy. Retrieved from: https://water.tallyfox.com/documents/restoringnatural-foundationsustain-green-economy-unep-2011

11. UNDESA. 2012b. (2020 July 19) A guidebook to the Green economy. Retrieved from : $\quad \mathrm{http} / /$ sustainabledevelopment.un.org/content/documents/743GE\%20 Issue $\% 20 \mathrm{nr} \% 202 . p d f$

12. Vilinovic, K. (2011). Rio +20 Conference and Slovakia in the process of an environment for Europe. Roads to a more sustainable future (Dobřís in the light of geographical and environmental research). Proceedings of a scientific conference with international participation. Bratislava: Institute of Geography SAS and STUŽ / SR.

13. Figge, F., Thorpe, A., S. Good, J. (2021). Us before me: A group level approach to the circular economy. Ecological Economy, 179, Article Number 106838.

14. Suzanne, E., Absi, N., Borodin, V. (2020). Towards circular economy in production planning: Challenges and opportunities. European Journal of Operational Research, 287(1), 168-190.

15. Demirel, P., Danisman, G, O. (2019). Eco-innovation and firm growth in the circular economy: Evidence from European small- and medium-sized enterprises. Business Strategy and Environment, 28(8), 1608-1618. 